Ecology of Cities and Towns: A Comparative Approach, Edited by Mark J.

McDonnell, Jürgen Breuste and Amy K. Hahs. Cambridge University Press

\title{
Chapter 8 \\ Responses of faunal assemblages to urbanisation: global research paradigms and an avian case study
}

Carla P. Catterall

Faculty of Environmental Sciences, Griffith University, Nathan, Qld. 4111, Australia.

\section{Introduction}

Urban areas worldwide share many features, including high human population densities, the presence of high levels of chemical input to air, water and soil, and the redirection and/or piping of above-ground water flows. As habitat for fauna, their other distinctive features include planted and maintained lawns and gardens, many simple and impervious surfaces (e.g., buildings, roads), patches of remnant native vegetation, and a liberal supply of human food scraps and wastes (McDonnell and Pickett, 1990; Marzluff et al., 2001 Nilon Chapter 10, van der Ree Chapter 11). These features also show characteristic spatial variation. In commercial and industrial domains, built structures dominate the available space, whereas in suburban residential areas, buildings are interspersed with gardens and lawns, which in turn may vary in size and nature. There is often an 'exurban' sprawl (Marzluff, 2001; Miller et al., 2001) containing residential areas which have larger allotment sizes, lower densities of dwellings, and more land occupied by lawns or vegetation. These global similarities are driven by trans-national export of technologies and cultures.

We might expect such similarities in environmental structure and function to produce worldwide similarities in the nature of urban wildlife assemblages. The notion that there are types of ecosystem which occur patchily across different continents ('biomes' sensu Begon et al., 1990) is familiar to ecological science. Examples include rainforests, savanna woodlands, heathlands, deserts, and saltmarshes. While the organisms in a particular biome may differ between continents in taxonomy, phylogeny, and diversity, they show parallel or convergent adaptations. For example, rainforests with tall buttressed trees, many vines, many fleshy-fruited plants and large-bodied frugivorous birds occur on many continents. Biomes of a particular type share aspects of ecosystem structure and function, such as physical context, vegetation structure, functional variety of organisms, and key disturbance agents and regimes. For example, periodic burning is an intrinsic part of ecosystem function in many savannas, but not in rainforests. The ecological patterns and processes that characterise particular biomes across continents have been identified through rigorous local ecological research into assemblage composition and ecological processes over many years, with a more general understanding being progressively built through synthesis.

The biomes described above are considered to be 'natural' ecosystems. However, interpretations of ecological processes within these ecosystems have varied, from a world view that assumes ecological equilibrium to a perspective which acknowledges that ongoing climate change and human intervention have had longstanding influences in many ecosystems (Williams 1993). The former view emphasized temporal stability and fine-tuned sets of interactions between climate and vegetation, or among co-evolved sets of interacting species, whereas the latter considers that areas viewed as 'natural' by European colonists of the past two hundred years may have been greatly influenced by the activities of aboriginal people for thousands of years previously (e.g., Williams, 1993; Bowman, 2000). Furthermore, aspects of biodiversity in many biomes may be tied to disturbance regimes, through the existence of spatial habitat mosaics whose elements are differing 
stages in post-disturbance succession (for example, following localised tree fall in rainforests or fire in Australian heathlands). In some cases, it is likely that humans have been the disturbance agent, for example by regularly burning (Bowman, 2000). Many apparently 'undisturbed' ecosystems may in fact be relics of earlier types of land use (Williams, 1993), the nature and extent of which have been forgotten following extirpation of aboriginal peoples by European settlers.

Urban areas, lying at the more human-dominated end of the spectrum, have historically been excluded from widespread recognition by ecologists as a worldwide ecosystem type. Consequently, the urban biome has been largely spurned as an interesting subject for rigorous scientific ecological research (McDonnell and Pickett, 1993; Niemela, 1999; Bowman and Marzluff, 2001). However, neither their relatively recent addition to many bio-regions, nor their high human density necessarily mean that urban ecosystems, across the globe, cannot share common species assembly rules and ecological processes. Clearly, the relative recency of urban areas means that evolution and co-evolution would be less important determinants of their species assembly than other processes such as colonisation, extinction, habitat selection, and environmental filtering. But this does not mean that urban areas are necessarily less amenable to rigorous ecological study, using established principles and methods, than other biomes.

In fact there are several reasons why it is important to treat urban biodiversity seriously as a subject of ecological research. Urban areas are typically located in productive (and hence biologically important) places, and they contain the last remaining individuals of some threatened species (Low 2002). Urban areas also contain novel combinations of environmental factors (Pickett et al., 1997, Pickett et al. Chapter 3), which have the potential to provide new insights into the processes which affect biodiversity. Furthermore, they are becoming spatially significant: the earth's human population is growing, and an increasing proportion are living in urban areas, whose areal extent is in turn increasing at a faster rate than urban population growth (Alberti et al., 2001; Marzluff et al., 2001; McDonnell and Pickett, 1990; Pickett et al., 1997).

If ecological research can identify global commonalities in the patterns of terrestrial biodiversity in urban areas, or in the processes which have the most influence on them, then this would aid prediction of likely future trends in newly urbanising regions. This understanding would also provide a better basis for planning, management and urban design to achieve better biodiversity outcomes (Pickett et al., 1997; Marzluff et al., 2001; Niemela, 1999, McDonnell and Hahs Chapter 5). Consequently, there have recently been several calls for researchers to apply the techniques and concepts developed within other ecosystems to reveal the ecological structures of urban populations, communities and ecosystems, and to elucidate the processes which underlie them (McDonnell et al., 1997; Marzluff et al., 2001). A failure to reveal useful information would indicate inadequacies in ecological principles or methods, not limitations to urban areas as a subject of scientific research.

Careful empirical investigations, within an analytical framework which is guided by existing ecological principles and testable hypotheses, should be able to reveal the ecological patterns and processes which characterise species assemblages in urban ecosystems (McDonnell et al., 1997; Bolger, 2001; Bowman and Marzluff, 2001). Here I present an example of such an investigation; a case study of the responses of bird assemblages to urbanisation in subtropical Australia. Then I discuss varying approaches that have been applied to the general question "what determines terrestrial biodiversity in urban areas?", and consider issues which are likely to be important in future studies of urban biotas, if we are to develop a global understanding of their ecology.

\section{Responses of bird assemblages to urbanisation in subtropical Australia: a case study}

\section{Urbanising south-east Queensland}


The urbanising subtropical region of eastern Australia is centred on the rapidly growing city of Brisbane (approximately $27^{\circ} 30^{\prime} \mathrm{S}, 153^{\circ} \mathrm{E}$ ), together with the adjacent urban areas of the Sunshine Coast and Gold Coast to its north and south, respectively. These lie mostly within south east Queensland, although the southern Gold Coast also extends into northern New South Wales. The region's human population size, around two million people in the early 1990s, increased by around 100,000 people per annum during much of the 1990s, making it the continent's fastest growing region (Catterall and Kingston, 1993). As in many Australian cities, housing allotments in most older residential areas are relatively large (typically 0.1 ha or more), and the growing human population is being accommodated in an expanding exurban sprawl, where allotments are often 0.2-10 ha or more.

European settlement of the region is relatively recent, having begun in the mid-1800s. It was rapidly followed by clearing of the formerly continuous forest cover ('bushland') for pasture and agriculture, mainly in lowland areas. From the mid-1900s, suburban development began to expand, in some places on land formerly cleared, and in others replacing remnant bushland. Ongoing deforestation rates have become a significant conservation issue in the region (Catterall et al., 1997b). However, due to historical vagaries of landowner inclination and circumstance, coupled with changing town planning approaches, patches of remnant bushland were, at least initially, retained in places. These have become encircled by residential suburbs where the land cover is a mixture of impervious surfaces, built structures, and large gardens that are nutrient-rich and well watered (due to added fertiliser and irrigation), containing mown grassy lawns sprinkled with scattered small trees and shrubs. Many of the component plants are cultivated species introduced from other parts of the world, although since the 1970s there has been an increased use of plants native to Australia (and sometimes to the region), often comprising taller, more densely planted, shrubs and trees. There has also been an increasing frequency of housing developments established beneath scattered original eucalypt trees which were retained when bushland was cleared prior to development.

The style of suburban land cover may be fairly uniform within areas of hectares to tens of hectares, but at broader scales of tens to hundreds of square kilometers, the region is a complex spatial mosaic of different forms of land cover. Some elements of this mosaic are the different types of residential development, each with its characteristic style and size of houses and gardens. Others include: business and industrial domains dominated by built structures; grassy parklands and golf courses with scattered trees; patches of cropland or remnant cleared pasture; and remnant native forest of different types. These differing forms of land cover constitute different types of potential fauna habitat, which provide resources of differing quality and quantity. All occur within patches of varying size. Prior to European settlement, the native vegetation cover was also a diverse mosaic of different vegetation types, in which eucalypt forests dominated, and rainforests were well-represented. Hence, patches of remnant vegetation also vary in nature.

\section{Analytical design framework for assessing responses of bird assemblages}

The case study considers how and why bird species assemblages in the urbanising greater Brisbane region are responding to the land cover changes which have accompanied human settlement. Birds, both in urban areas and elsewhere, are a flagship group which provides a source of pleasure and fascination to many people who otherwise have no special interest in nature (Catterall 1991). Many people like to feel that they are building or maintaining gardens that are attractive to native birds, and which help support them. Birds are also functionally diverse, relatively common, easily and cost-effectively surveyed and identified, taxonomically stable, and the ecology of individual species is relatively well-known. Hence they are well-suited to this type of study. 
A series of research projects has investigated the ways in which birds respond to deforestation and urbanisation in the study region (including Catterall et al., 1989, 1991, 1993, 1997a, 1998, 2002, 2004; Park, 1994; Bentley and Catterall, 1997; Green and Catterall, 1998; Sewell and Catterall, 1998; Oertel, 1998; Martin and Catterall, 2001; Piper and Catterall, 2003, 2004). In this paper I both draw upon their findings and present new analyses of data compiled from seven of these studies (Table 1). Each project involved a quantitative and controlled comparison of selected attributes of the target biota (in this case the composition, relative frequency and abundance of bird species), across differing forms of land cover (an "observational experiment" sensu Eberhardt and Thomas, 1991), using the following common design protocol.

Table 1

First, land cover types to be compared were chosen (these are the controlling factors of central interest), each defined by criteria relating to both local habitat structure and spatial context. Replicate sites were then located for each land cover type. As far as possible, replicates were spatially well-separated, to allow them to represent independent sets of birds, and sites from different land cover types were interspersed. Careful site selection was used to achieve experimental control (again, as far as possible) by limiting or stratifying the variation in other factors (e.g., elevation, proximity to water) whose influence on the avifauna might otherwise confound and complicate the results. Standardised sampling at each site (in this case, a temporal series of visual transect counts) was then used to measure a number of response variables (aspects of the avifauna). Each study included a subset of the land cover types listed in Table 1; in some cases these were more finely subdivided, and some included additional types not analysed here (e.g., forest edges, regenerating or reforested areas).

The projects compiled for this paper provide data for 18 combinations of land cover and study, spanning a 15-year period (1985-2000) (Table 1). Six of the component studies were also summarised in Catterall (2004) and further data (rainforest, pasture) were added from the seventh study (Catterall et al., 2004). All studies used a similar measurement of the avifauna (Table 1; a count of individuals of each species by an observer during six visits to a small-scale transect (100 $\mathrm{X} 30 \mathrm{~m}$ ). In the present overview, all avifauna measurements are based on the presence/absence of each bird species at a site (across all visits), in order to minimise the effects of variation between observers (although analysing the data using abundance gave similar results). Across all 263 sites, 144 bird species were recorded.

\section{Selected results and outcomes}

Site-level bird species richness was similar across most land cover types (Figure 1). However, pasture and bare suburbs both had site-specific species richness around half of that seen in either well-vegetated suburbs or forests. Species richness tended to peak in eucalypt forest remnants of area 10-20 ha, consistent with other recent studies which have reported greatest faunal species richness at intermediate points along urbanisation gradients (Blair and Launer, 1997; Niemela, 1999; Blair, 2001; Germaine and Wakeling, 2001; Crooks et al., 2004), probably because the areas contained both 'forest' and 'urban' species. However, this was a minor difference compared with the large reduction in the two simplest habitats. Species richness within eucalypt forest also varied considerably between sites in riparian and upslope areas (Bentley and Catterall, 1997; not shown in Figure 1).

Figure 1

In contrast, the various land cover types showed much stronger differences in both their species composition and the occurrence of species within particular functional groups (Figure 1, Figure 2, Table 2). All but three of the 28 pairwise comparisons between land cover types showed a strong difference in species composition $(\mathrm{P}<0.001$, Table 2$)$. The exceptions (pairs which did not differ 
significantly) were: eucalypt forest tracts above 100 ha and eucalypt forest remnants 10-20 ha; eucalypt forest remnants 1-2 ha and those 4-10 ha; and eucalypt forest remnants 1-2 ha and treed (well-vegetated) suburbs.

Figure 2, Table 2

Sites within suburbs (both bare and well-vegetated) contained more exotic species and more seedeaters than other forms of land cover (Figure 1). These included the ubiquitous house sparrow and common starling (Figure 2), and others (including rock dove Columba livia, spotted turtle-dove Streptopelia chinensis and common mynah Acridotheres tristis). Exotic species were around half of the low overall richness in bare suburbs, but in treed suburbs a similar number of species (1-2 per site) comprised only a small proportion of the total avifauna. The relatively small number of native species which commonly occurred in bare suburbs included some which have recently increased in range and/or abundance (such as the willie wagtail Rhipidura leucophrys and Australian magpie-lark Grallina cyanoleuca). Catterall (2004) labeled the species which characterised bare suburbs as 'new arrivals'.

The native avifauna of treed suburbs was dominated by a range of different large-bodied species (Figure 1), such as the rainbow lorikeet, pale-headed rosella and noisy miner (Figure 2), and others such as grey butcherbird Cracticus torquatus, scaly-breasted lorikeet Trichoglossus chlorolepidotus, Australian magpie Gymnorhina tibicen and laughing kookaburra Dacelo novaeguineae (see also Sewell and Catterall, 1998; Catterall, 2004). This group of species was dubbed 'aussi icons' by Catterall (2004), because they are widely known and admired by everyday Australians. A number of them feed, at least in part, on other vertebrates.

At the other end of the spectrum, both large areas of intact eucalypt forest and rainforest areas were characterised by a high diversity of small-bodied, foliage-feeding insectivores, especially those which feed in the canopy and mid-storey (Figure 1). These include a number of honeyeaters (Meliphagidae), pardolates, thornbills and allies (Pardalotidae), flycatchers (Dicruridae), whistlers (Pachycephalidae), robins (Petroicidae) and fairy-wrens (Maluridae). Eucalypt forest and rainforest had similar numbers of species per site within this functional group, although there was considerable turnover between the two habitats in species identity. For example, the brown gerygone and Lewin's honeyeater occurred mainly in rainforest, the white-throated and yellowfaced honeyeaters were confined to eucalypt forest, and the golden whistler and grey fantail occurred in both (Figure 2). This species group was termed 'neglected foliphiles' by Catterall (2004), since their foliage-feeding habits, small body size, and restriction to intact forest have rendered them virtually invisible to most human inhabitants of urban areas, even though many of these species are very common in remnant forest, and well known to bird observers.

Dominance of urban avifaunas by a few, widespread, species has been reported worldwide (Marzluff, 2001). This creates a global biotic homogenisation of urban areas with respect to bird species composition (Blair, 2001; Crooks et al., 2004). However, in the study region this phenomenon was restricted to bare suburbs. In contrast, treed suburbs supported many native species. Also, the occurrence of these birds was not clearly related to whether or not the suburban vegetation mainly consisted of native plants (see also Catterall et al., 1989; Parsons et al., 2004). The provision of suitable resources by plant species appears to be of more direct importance than their geographical origin.

Sewell and Catterall (1998) identified four sources of species for assembling urban bird communities in the study region. (1) Species which were common prior to any urbanisation and which continue to use only the remaining fragments of the original habitat. (2) Species formerly rare or absent for which the urban habitats are more suitable (e.g. built areas, grassland or widelyspaced trees), including passive colonists imported by humans, active colonists from suitable 
habitat in nearby regions, or local expanders which formerly occurred only in suitably open patches scattered within the original forested habitat. (3) Species which previously used elements of the original habitat (e.g. scattered fleshy-fruited or nectar-bearing trees) in a manner that can also be applied to the urban habitats. (4) Species formerly present which can use urban areas because they have changed their behaviour as a result of learning.

Within the suburban matrix, habitat structure and resource availability must be important determinants of which species use different forms of suburban development. There is some indication that patch size of suburban land cover types also plays a role. When surveys were conducted within areas where there was 20 ha or more of relatively uniform land cover (either bare or treed suburb) there were clear differences in the avifauna (Figures 1 and 2, Table 2). However, when sites within the suburban habitat were selected on the basis of habitat immediately around the 0.3 ha transect, there were negligible avifaunal differences between bare and treed areas (Catterall et al., 1991; discussed by Sewell and Catterall, 1998).

For remnant patches of eucalypt forest, the smallest size category (1-2 ha) had a very similar avifauna to that of the treed suburbs, whereas the largest size (10-20 ha) had a very similar avifauna to the large eucalypt forest tracts (Figures 1 and 2, Table 2). Remnants 4-10 ha in size were transitional. Thus, there appears to be a threshold size for eucalypt forest remnants of around 5-10 ha, at which their bird assemblages become very similar, especially in functional terms, to areas of intact forest (Figure 3; see also Martin and Catterall, 2001; Piper and Catterall, 2003). Furthermore, there is a spatial scaling transition at around 1-2 ha, where the role of a very small forest patch in providing habitat for avifauna is very similar to the role of a liberal supply of scattered individual trees or shrubs, without the consolidated structure of intact forest.

In practical terms, this means that the retention or creation of very small $(<2 \mathrm{ha})$ patches of eucalypt forest habitat are both likely to have similar biodiversity outcomes to planting or retaining individual elements (trees and shrubs) within urban developments, gardens or landscaping projects. And it also means that these biodiversity outcomes are different from those which would follow the retention or creation of larger forest patches. The latter will provide habitat for a forest avifauna of neglected foliphiles, whereas the former results in a distinctive, non-transitional assemblage of large-bodied, native species, dominated by the aussi icons. This species mix also resembles that found at the edges of large forest patches in the study region (Catterall et al., 1991, 1997; Piper and Catterall, 2003).

Figure 3

An important factor contributing to the distinctive differences in the bird species composition of treed suburbs and very small remnants is their occupancy by a particular species, the noisy miner (Catterall et al., 2002; Catterall, 2004; Piper and Catterall, 2003). The noisy miner is a native, large-bodied (63 g), foliage-feeding insectivore which establishes cooperatively-breeding colonies. Their group territories are vigorously defended with a uniquely high level of interspecific aggression (Dow, 1977). Experimental removals have confirmed that the noisy miner is responsible for the exclusion of most smaller-bodied species, both in the study region (Catterall et al., unpublished data) and elsewhere (Grey et al., 1997, 1998). Across a similar range of sites to that described in the present paper, the abundance of noisy miners showed a strong negative correlation with the number of smaller-bodied birds, and a weaker positive correlation with the number of larger-bodied birds (Catterall, 2004). However, if sites with similar abundances of noisy miners are considered, larger forest patches still support more small-bodied species than small remnants and well-vegetated suburbs, indicating that other factors are also involved (Catterall 2004). 
The factors underlying changes in the bird assemblages of small forest remnants, at least in the greater Brisbane region, appear to be largely a consequence of behavioural processes (habitat selection and inter-specific interactions) and resource availability rather than the more commonlycited (Marzluff, 2001) processes of small-population dynamics and top-down predator control. This can be suggested for several reasons. First, many of the small-bodied 'foliphile' species are non-breeding winter immigrants (Catterall et al., 1997a, 1998). Second, behavioural exclusion by noisy miners is clearly important; the threshold remnant size of around 10 ha corresponds with the noisy miner edge penetration distance of 100-200 m, suggesting that the small remnants are essentially all "edge" habitat (Piper and Catterall, 2003). Third, it seems unlikely that metapopulation dynamics could predict the observed sharp response threshold shared by many species. Fourth, even the non-migratory small-bodied species do not appear to be poor dispersers, and many are considered to be locally nomadic (Catterall et al., 1998). Other possible reasons were discussed by Catterall et al (1997a). Furthermore, the foliphiles, although many undertake longrange movements, show finely-tuned patterns of local habitat choice. For example, the proximity of a suburban area to remnant forest does not affect its use by these species (Catterall et al., 1991).

I do not mean to suggest that no species show area-sensitivity at larger ( $>20$ ha) patch sizes. Certain species (e.g. eastern yellow robin, white-throated treecreeper and weebill, Catterall et al., 1997 and unpublished data) appear to require larger patches. Furthermore, breeding migrants and year-round residents in the study region show greater area-sensitivity than winter immigrants (Bentley and Catterall, 1997). Apart from exclusion by noisy miners, sensitivity to patch area in some of these species may also occur if a patch is too small for the home range of an individual or breeding group (as suggested by Hostetler, 2001), and for a few of them may involve small-patch population dynamics. Furthermore, we have insufficient information about changes that occur as remnant patches age. Many of the patches surveyed in the case study would be less than 20 years old. In future years, there may be habitat change (perhaps driven by altered fire regimes and/or vegetation recruitment patterns), and further increases in numbers of noisy miners (Catterall et al., 2002). Such changes may alter the area threshold for change in avian assemblage in remnant forest. Within patches close to the current size threshold (5-20 ha), differences in shape, isolation, and local habitat may be important, but have not been systematically investigated.

Additionally, population processes may be contributing to changes at broader spatio-temporal scales, since many of the larger-bodied 'aussi icon' birds of the well-vegetated suburbs, edges, and very small remnants are also nest predators, whose presence is associated with a higher predation rate at artificial nests (Piper and Catterall, 2004). This may result in a lowered total breeding output and hence a reduced pool of colonists, which could in turn affect population densities of residents and summer migrants across all remnant bushland areas. However, most species involved are multi-brooded, and not enough is known about the role of re-nesting and early survivorship to make reliable predictions.

The patterns and processes described here must occur widely along coastal eastern Australia. In Sydney (around $700 \mathrm{~km}$ to the south of the study region), the avian assemblages show similar patterns of variation in suburbs and forest remnants, similar effects of the noisy miner, and somewhat similar concerns about nest predation rates (Parsons and Major, 2004, Parsons et al., 2004, Major et al., 1996). The entire subtropical Australian coastal zone is becoming rapidly urbanised, and there is a risk that inappropriate development will lead to widespread declines in avian biodiversity.

Catterall et al. (2003) and Catterall (2004) made various management recommendations applicable to this region, including the following. Sustaining avian biodiversity within urban areas requires a diverse habitat mosaic (including sufficiently large areas of different types of native vegetation, and different types of suburban development - a focus on beta diversity). Garden plantings cannot 
be regarded as a substitute for conserving remnant bushland, but have a distinctive and new set of faunal values. Restored forest patches below 5 ha are unlikely to have different biodiversity value (at least for birds) from garden plantings. More public education is needed about the differing roles of the 'aussi icon' and 'foliphile' species. There would be biodiversity benefits from removing the legislative protection which currently prevents humane culling of the noisy miner. More generally, they concluded that urban design projects need to be conducted at ecologically meaningful spatial scales, and there needs to be more focus on the proportion of the total land area which supports native forest.

\section{Urbanisation and biodiversity: approaches, paradigms, and global syntheses}

To obtain answers to the general question 'what determines terrestrial biodiversity in urban areas?', it is first necessary to establish a framework within which similarities and differences in assemblage structure and causal processes can be assessed, across taxa and across regions. Until recently, studies of urban biodiversity were predominantly descriptive accounts of the biota within a region (Marzluff, 2001), rather than investigations aimed at elucidating factors which underlie the composition, distribution and abundance of the urban biota. Therefore, the study of urban biotas has often lacked a tradition of generalisation, or of building an understanding which could enable predictions of the consequences for biodiversity of different forms of urban design. More recently, there has been a rapidly growing body of quantitative research into spatial patterns of variation in terrestrial urban biotic assemblages, especially bird assemblages, and environmental parameters (e.g., Blair, 2001; Germaine and Wakeling, 2001; Hostetler and Knowles-Yanez, 2003; Bolger, 2001, 2002; Niemela et al., 2002; Patten and Bolger, 2003, Crooks et al., 2004, Hochuli et al., 2004; Parsons et al., 2004; Lim and Sodhi, 2004; this study). Continued growth in this research effort will soon offer opportunities for synthesis and meta-analysis, and hence for an improved global understanding.

However, the success of such syntheses will also depend on the nature and quality of the contributing research projects. Here I discuss four elements of importance to obtaining general insights into the ecology of urban biotas: unifying theoretical approaches, sound analytical designs, comparable forms of response variable, and the definition and selection of meaningful and comparable environmental factors. These considerations are inter-related, and addressing each on its own will be of limited value.

\section{Unifying theoretical approaches}

Theoretical paradigms provide a framework which stimulates structured tests of the effects of specific environmental factors on particular aspects of biodiversity. Similar tests that are conducted in different regions, or with different taxa, provide information on whether useful generalisations are possible. During the past two decades, two major ecological paradigms have been widely applied to urban ecosystems: habitat fragmentation and urban-rural gradients.

Theories of habitat fragmentation (e.g. Saunders et al., 1991; Fahrig, 1999) have been applied to many different biomes, whether fragmented by humans or by other agents such as climate or topography (Watson, 2002). They typically view landscapes as binary mosaics in which patches of one type of environment are surrounded by a matrix of a second type. Most frequently, the focus is on the fate of native biota within scattered areas of remnant pre-European vegetation, which remain after much of the landscape has been cleared for human use. However, similar processes would apply to patches of restored habitat. A variety of different ecological processes have been hypothesised as factors which could cause change in species assemblages within such habitat fragments, and specific predictions vary, and are still under debate (Harrison and Bruna, 1999; Fahrig, 1999; Bolger, 2002). However, many refer to the same environmental factors: size, shape, 
age, isolation, and aggregated total area of the fragments, and the focus is on understanding or predicting the persistence of species which require only that habitat type. These species are expected to be more likely to persist or be colonisers in fragments which are larger, less linear, less isolated, set within well-vegetated landscapes, and younger (if remnant habitat) or older (if created or restored habitat). However these factors may show complex interactions, and effects would also depend on a species' dispersal capabilities.

Habitat fragmentation theories can most readily be applied to urban ecosystems by focusing on fragments of native vegetation within the urban matrix, and testing for differences in species and assemblages between fragments of differing size, shape, etc. This approach was incorporated into the case study described here. However, there are serious limitations to its general usefulness in urban ecology. First, fragmentation theory is silent concerning species that might be winners or losers in terms of their ability to survive or thrive within the urban matrix, and on the nature of the ecological processes which might determine this. Hence, it neglects a large part of the urban ecosystem. Second, many applications of the theory falsely assume that the matrix is both inhospitable and non-interactive. Actually, where vegetation remnants are set within suburbs containing planted gardens or parkland, the matrix may variously improve or inhibit dispersal (due to interactions with species present in the suburbs), contribute new species to the vegetation fragment (from those introduced to the suburbs), contribute to longer-term changes in the quality of the remnant vegetation (e.g. through predation or competition involving dominant plant species), and interact with the fragment to provide distinctive edge habitat.

In contrast, the urban-rural gradient approach (McDonnell and Pickett, 1990; McDonnell et al., 1993) is focused on all environmental attributes of urban ecosystems. Its basic premises are, first, a recognition that within all ecosystems there is measurable quantitative variation in these attributes (which could be abiotic such as temperature or soil nutrient levels, or biotic such as tree cover), which is correlated with measurable variation in biotic responses (such as species' frequencies and ecological processes). Second, these relationships can be scientifically investigated using the gradient analysis techniques pioneered by plant ecologists. Third, such analyses will suggest causal relationships, whose operation can be tested through further, more closely targeted measurements and manipulative experiments (McDonnell et al., 1997; Pickett et al., 1997).

It was further suggested that spatial distance may often correspond with environmental difference, since cities often have a densely built urban core which is surrounded by concentric rings of diminishing landscape modification (McDonnell et al., 1993, 1997). At the outer extreme lie the 'rural' lands, which define the non-urban end of the gradient. However, there are several potential problems with this. First, due to the selective placement of many cities along coastlines and at river mouths, there are underlying gradients in environmental characteristics which are correlated (and hence confounded) with effects that are a consequence of distance from the urban core.

Second, the non-urban spatial extreme can itself show a level of variation in environmental features which exceeds their variation along the urban-rural gradient, thereby greatly reducing its usefulness as a simple reference point. An example of this is the pasture and forest habitats which were both present in the Brisbane region case study as non-urban environments. Third, it may be an unnecessary oversimplification to use spatial distance as an indirect surrogate for environmental gradients. Many cities, especially in rapidly developing areas, show spatial mosaics rather than gradients, with urban patches abutting large areas of native vegetation, along abrupt edges (Blair, 2001; Bolger et al., 2001; this study). Using surrogate spatial gradients assumes that all environmental factors vary in the same way with distance and may prevent discrimination among alternative combinations (Alberti et al., 2001). This can limit the opportunity to develop and experimentally test ideas concerning causal mechanisms, and suggestions for novel urban designs that promote synergies between biodiversity and urbanisation. 
Many authors of recent papers (see earlier list) on the responses of faunal assemblages to urbanisation have described their work as studying an urban gradient. Interpretations of the meaning of the gradient have included: (1) sites within remnant vegetation patches located at varying distances from an urban centre (e.g. McDonnell et al., 1993, 1997; Niemela, 1999; Niemela et al., 2002); (2) interior sites within very large remnant vegetation patches, through forest edges to smaller patches of diminishing size (e.g. Patten and Bolger, 2003); (3) sites within suburban areas, through small remnants, to larger forest areas (Crooks et al., 2004); (4) sites whose land cover varies from highly built and poorly vegetated, through residential areas with gardens, recreational areas, to remnant native vegetation (e.g. Blair and Launer, 1997; Blair, 2001); (5) sites within urban areas (excluding remnant forest) that varied in the amount of built structure (Lim and Sodhi, 2004); (6) sites that were spatially distributed with no clear rationale for their locations (Reynaud and Thiolouse, 2000; Germaine and Wakeling, 2001; Melles et al., 2003). In some cases, authors seem to have regarded studying variation along the urban gradient as an end in itself rather than as the means towards an end of understanding causal relationships. Wide application of such an approach will make comparisons across studies very difficult.

In the Brisbane region case study, there were elements of two gradients: the range of forest patch sizes (1-2 ha through to $>100 \mathrm{ha}$ ), and the range of local tree canopy cover (from bare suburbs, through treed suburbs to eucalypt forest to rainforest).

Both the fragmentation and urban-rural gradient paradigms have stimulated problem-centred scientific research within urban ecosystems, and hence both represent a significant advance over simple descriptions of the biota of urban areas. Clearly, both are useful in stimulating and guiding research into different processes which govern biodiversity in urban ecosystems. However, neither directly provides a predictive tool for urban planning, and there is a risk of perverse outcomes if they are simplistically applied without verification of the underlying causal processes (see also Bolger, 2001, 2002). Research stimulated by these theoretical approaches may ultimately lead to new and different forms of theory or generalisation concerning the ecology of urban areas.

\section{Sound analytical designs}

More research effort is needed to reveal the nature of the dominant ecological processes in urban areas. However, to provide useful information, these studies need to be set in a context of rigorous empirical experimental design (McDonnell et al., 1997; Bolger, 2001; Bowman and Marzluff, 2001; Marzluff et al., 2001). Such designs need the capacity to reveal both region-specific patterns and the processes which underly them. Testing of hypotheses, derived either from theory or from observation and logical reasoning, is an important component of reaching a mechanistic understanding of how urban ecosystems function. Urban areas offer considerable opportunities for mensurative experiments (sensu Eberhardt and Thomas, 1991) which make careful use of the serendipitous occurrence of different patches of a particular type of urban development as the experimental treatments (Pickett et al., 1997; Marzluff et al., 2001).

This was the approach adopted in the Brisbane region case study. It allows predictions of the outcome of land use change on local biotas, through the substitution of space for time (e.g. Pickett, 1989). For example, bird species whose abundance is higher in cleared and developed areas than in bushland are frequently also those whose abundance has increased over time following intensive land use (Catterall et al., 1998). The approach resembles that advocated by Miller et al. (2001), except for their differing endpoint of predictive spatial modeling compared with developing a predictive understanding of process (this study). The application of such an approach across a diverse range of taxa was discussed by Catterall et al. (2004). 
There are several aspects to rigorous empirical design in the study of the responses of biotic assemblages to environmental factors (Eberhardt and Thomas, 1991; Quinn and Keough, 2002; Catterall et al., 2004). Along with the formulation of clear research questions or hypotheses, a clear and appropriate choice of both response (dependent) variables and explanatory (independent; environmental) variables is needed. Environmental variables could be either continuous in nature (as is the case in the simplest interpretation of the urban-rural gradient approach) or discontinuous, in the form of discrete treatments. The former may be either graded levels of a continuous variable or of a set of multiple co-varying factors; the latter are different environments for which intermediate states are rare. There needs to be sufficient replication, to allow the detection of statistically significant effects, to allow valid generalisation, and to allow reliable conclusions to be drawn in cases where there appears to be no effect. Confounding factors (environmental variables which are correlated with a hypothesized explanatory variable, and which would hence complicate the interpretation of apparent relationships) need to be avoided. When this is not possible, they need to be identified and considered. Related to this issue is the need for independence of replicates, which often means sufficient spatial separation. Finally, appropriate measurement regimes are needed for both response and explanatory variables.

A single well-designed study, however, cannot address more than a few aspects of the effects of human settlement within a region (Miller et al., 2001). To gain a useful understanding of the operation of processes which underlie patterns of urban biodiversity will also require serial research projects which, according to the usual pattern of scientific investigation, begin with one set of questions, which may be general and open-ended, and then proceed to more specific questions and tests, as ideas concerning structure and process develop (and others are rejected). This requires a progressive series of studies, typically beginning with the documentation of pattern, and ultimately leading to experimental manipulations, which provide the most conclusive tests of process (McDonnell et al., 1997; Bolger, 2001; Bowman and Marzluff, 2001).

In the case study, progress towards understanding the effects of urbanisation on the regional and local avifauna involved a such series of projects: identification of major forms of land cover change (e.g. Catterall et al., 1991; Catterall et al., 1997b; Sewell and Catterall, 1998); analytical assessments of the nature of variation in bird assemblages corresponding with these changes (e.g. Catterall et al., 1998; Sewell and Catterall, 1998; Bentley and Catterall, 1997; Martin and Catterall, 2001); formulation of hypotheses concerning mechanisms (e.g., Catterall et al., 1997a); and tests of these hypotheses with either refined and targeted observational comparisons (e.g. Piper and Catterall, 2003) or with field experiments (Catterall et al.,unpublished). Understanding the patterns and processes has lead to practical suggestions for management (Catterall et al., 2003; Catterall, 2004).

Such a sequence of studies may reveal causal processes that are either inconsistent with, or of a different nature to, those initially hypothesized. For example, the discovery that noisy miners are a major cause of reduced bird diversity in small forest fragments of the Brisbane region would not have been predicted using fragmentation theory (Piper and Catterall, 2003). Likewise, Patten and Bolger (2003), testing ideas developed from previous studies (e.g. Bolger, 2001, 2002; Crooks et al., 2004 and references therein) found that declines in bird species in small coastal sage-scrub remnants in California could not be explained by the expected processes of nest predation. In New York, McDonnell et al. (1997) reviewed a series of studies to show that variation in nitrogen mineralisation with distance from the urban core occurred in the opposite direction to that originally predicted, and conducted experiments to reveal the reason for this. In all of these cases, there remained further uncertainties and knowledge gaps to be filled.

Many studies of terrestrial urban biodiversity have been based on designs which do not meet the criteria discussed above. More generally, a high level of scientific rigor has not always been 
required of research which addresses socially significant ecological issues relating to human impact, compared with that applied to research in basic ecology. In part, this may be associated with the historical rejection of human-impacted areas by ecologists as appropriate subjects for study. There is a need to reverse this perception, because the conclusions from these research designs are used to guide actions which may have significant long-term impacts on human society and the environment. If these conclusions are incorrect as a result of flawed research designs or interpretations, then the cost may also be significant (and much greater than the cost of drawing an incorrect conclusion from a study of, for instance, the evolution of reproductive behaviour). For example, if it was demonstrated that biodiversity had declined in small urban remnants of native vegetation, and an interpretation was then made that the causal process was a lack of immigration to offset stochastic small-population extinctions, then the provision of habitat corridor linkages between remnants could be an effective solution. However, if this interpretation was incorrect, and the declines were caused by habitat degradation or edge effects, then corridor construction would be an ineffective waste of resources (Harrison and Bruna, 1999) unless the corridors had other functions.

Thorough, region-specific, research is essential to inform local planning and management. However, it cannot provide global insights or generalisations. These require the integration of results from different places and taxa. This is only possible where there are some common elements in research design, and in the measurement of both environmental and biotic variables.

\section{Comparable forms of response variable}

A major obstacle to making cross-regional comparisons of species-level measurements is the lack of species in common between different regions and different continents. An exception to this is the small set of species which have emerged in literature reviews to be near universally advantaged by intensive urban development (e.g. among birds, the house sparrow, rock dove and common starling, Blair, 2001; Marzluff, 2001).

To account for the large number of other species, the most common solution has been the study of simple variables such as species richness, total abundance, and diversity indices. Marzluff's (2001) review found variable and inconsistent patterns in these metrics across urbanisation gradients. Their use involves the loss of significant ecological information. For example, in the Brisbane region case study, most forms of better vegetated land (including both treed suburbs and differently sized forest patches) had similar species richness, but varied greatly in species composition. Furthermore, the loss of species-specific functional information associated with these metrics inhibits the construction of mechanistic hypotheses and the scientific pursuit of processes which underlie the observed patterns.

The use of functional groups of species, if clearly based on ecological characteristics, can overcome this problem. In the case study, measured species richness within functional groupings based on feeding ecology, body size, and geographic origin showed clear and differing responses to environmental changes associated with different forms of urbanisation. Marzluff's (2001) review also found more worldwide consistencies when birds' responses were compared at functional group level (exotic species, predators and parasites, interior nesters, ground nesters, cavity nesters). Other possible bases for grouping include movement patterns and geographical range size. Such classifications are increasingly being used (e.g., Reynaud and Thiolouse, 2000; Melles et al., 2003; Lim and Sodhi, 2004). They are increasingly becoming possible for birds worldwide, as compendia of continental avifaunas, which include information on species' life styles, are becoming available. They provide a common measurement for species on different continents which are taxonomically and phylogenetically distant, but which fill very similar ecological roles as a result of convergent evolution. They also show promise for use in tropical regions, where a high ambient 
species richness, together with a large number of uncommon species, render it difficult to individually assess species-specific responses.

However, the effective use of functional groupings in cross-regional comparisons requires systems of functional classification that are both ecologically meaningful and applicable in a worldwide context. The most commonly used classification so far has been the dichotomy between 'nonnative' and 'native'. However, this has perhaps the least predictive power, and verges on tautology; by showing that urban areas often contain more introduced species, we show that species which live and move successfully with humans do well in cities. The distinction between these two categories will become increasingly complex as more species expand their ranges in response to the availability of anthropogenically-modified habitat. It could be more useful to understand what ecological properties enable a species to colonise and live in cities. Classifications based on diet and nesting biology have a clear ecological meaning, but the actual groupings have varied considerably among authors, and the criteria for group membership are rarely stated. For taxa other than birds, there is often insufficient information to allow functional classification of species.

For all taxa, it would also be useful to develop the 'response-guild' concept in a manner which can be consistently applied across regions. Response guilds are empirically-based classifications of individually analysed species according to their patterns of response to particular environmental change, such as deforestation or urbanisation (see for example Bentley and Catterall, 1997; Catterall et al., 1998; Sewell and Catterall, 1998; Bolger, 2002; Crooks et al., 2004; Parsons et al., 2004). Terms used for response guilds have included 'forest indicators', 'generalists', 'areasensitive', 'forest-interior', 'urbanisation-sensitive', 'developed land' and 'urban' species. The criteria for classification and the type of information used as its basis have varied widely, making this another area where comparable classifications would be useful. However, if species can be categorised into both response-guilds and functional groups, then the relationship between the two can be assessed using analyses based on cross-tabulation. This approach enables comparison of species-level responses across regions, even if there are no species in common.

An alternative approach to the species problem may be through multivariate classification and ordination. During the past decade, there has been a rapid development of computer-based multivariate techniques for efficiently processing large data sets with many species, including methods suited to ecological survey data (eg Clarke, 1993; Quinn and Keogh, 2002). These have enabled a greater focus on species composition and its relationships with a wide range of environmental variables (e.g., Reynaud and Thiolouse, 2000; Blair, 2001; Germaine and Wakeling, 2001; Martin and Catterall, 2001; Melles et al., 2003; Lim and Sodhi, 2004; Parsons et al., 2004). Such analyses aim to derive simpler patterns from complex data. But there are many technical issues which may affect their success and interpretation (Quinn and Keogh, 2002). There is also a risk that multivariate ordination will supplant the provision of tabulated summaries of individual species' responses, which are useful in comparative reviews. However, if set in the context of a clear design, these multivariate techniques offer a potential for the use of metrics for the relative biotic distance (based on species composition) of environmentally modified sites from reference sites which have been chosen to set the extremes on an urban gradient. Such distance measurements might then be used in cross-regional comparisons.

\section{Definition and selection of meaningful and comparable environmental factors}

For effective global comparison, sites also needs to have comparable explanatory (environmental) variation in different regions. This is the most difficult current challenge facing comparative research in urban biodiversity. It requires both an explicit recognition and a quantitative description of the environmental differences between experimental treatments, or of the 
environmental properties of a gradient under study. Furthermore, the measurements need to have ecological meaning.

Marzluff et al. (2001) concluded that the lack of environmental measurements was a major deficit in $41 \%$ of 101 reviewed studies of the effects of urbanisation on birds. However, many more recent studies of urban biodiversity (e.g. those cited above) have measured a variety of aspects of environmental variation at spatial scales from local (e.g. within-site percent cover of built structures, trees, and grass, at a scale of squared metres) to landscape (e.g., habitat patch size, shape indices, and percent vegetation cover, within a radius of hundreds of metres or more, of native vegetation, built structures, and water). Within the past decade, the increased availability of remotely-sensed data and GIS-based metrics have made landscape-scale measurements widely feasible (e.g., Alberti et al., 2001). However, their availability now far exceeds our ability to meaningfully relate them to ecological processes (Miller et al., 2001).

An important feature of urban ecosystems is the hierarchical multi-scale spatial heterogeneity of urban environments (see Alberti, 2001; Miller, 2001; Hostetler, 2001 for comprehensive discussions). One consequence of this is that analyses relating measurements of biota to measurements of environment will be affected by both the spatial scale selected for measurement of the biota (e.g. a 0.1 ha area compared with a 50 ha area) and that selected for measurement of the environment. A species may be sensitive to the presence of a habitat area at a scale which differs from that selected for measurement. For example, if the presence of a 1 ha vegetation patch provides habitat for a species which would otherwise be absent from a built-up area, but the biotic measurements are made over 5 ha (not uncommon in bird census projects), and the land cover is mapped at a scale of 1:100 000 (unlikely to detect habitat patches $<10 \mathrm{ha}$ ), then no level of numerical or statistical sophistication will be of use in elucidating the processes important to that component of biodiversity. If, in contrast, a species responds to habitat patches only above 10 ha, this could be difficult to detect if measured landscape habitat cover is aggregated over patches above 1 ha. If area-sensitive species are to be assessed by using relatively small sampling units (as in many bird transects), it is important to control the size of the patch of uniform land cover around a sampling site. While area-sensitivity is often considered in relation to forest-dependent species within remnant patches, it would also apply to species from other response guilds. For example, a 'suburban' species may show positive responses to the presence of built structure over several hectares, but be unaffected by a small cluster of houses.

The complexity is increased when surveys of biotic assemblages are conducted across points which vary in terms of many different environmental parameters. Even multivariate ordination techniques are unlikely to be able to produce clear indications of underlying ecological processes when confronted with the joint complexities of spatial scale/heterogeneity issues and multiple (and potentially interacting) underlying environmental gradients. There is a simple solution to this problem: careful and controlled design and site choice (see above). We need to choose site types to address clear questions and hypotheses. The selection of a limited number of potentially meaningful aspects of environmental variation, control over the remainder, and careful placement of sites within areas of uniform habitat whose minimum size has been carefully considered are all important (see also Miller, 2001; Hostetler, 2001)

The outcome also depends on the criteria used for the categories of habitat mapped. It will be extremely difficult to compare the findings of studies in different regions if there is no means of calibrating the magnitude and scale of environmental variation between studies. Ecologically meaningful attributes need to be measured, in a broadly similar manner across different studies. Local, site-specific measurements of features, such as percent cover of grass, tree canopy, and built structures, are often broadly comparable across studies in different regions. These are measures of, or surrogates for, factors known from autecological studies to be important to individuals and 
populations of many terrestrial vertebrates. However, the treatment of landscape-scale attributes has been more variable. Measurements have included housing density and the proportion of area within a given radius covered by: buildings, different botanical associations of remnant vegetation, parks, and managed green open spaces. A particular problem is the use of culture-specific terms such as 'park' and 'greenspace' which lack objective definitions in terms of the features important to biota. For example, in different places, either of these terms could mean an area of conserved remnant native vegetation, or a grassy mown area with or without scattered trees, even a grassed football field.

It would be useful to develop a global typology of urban land cover, which both recognises major formations which occur worldwide, and provides a quantitative description of decision criteria for these, so that any particular area can be consistently classified by different observers. A typology would deal with the large amount of co-variation which occurs in environmental variables in urban areas, and with their spatial patchiness. A successful global typology would need to be operationally useful, provide repeatable measurement values, be not too complex, be relevant to both developed and developing countries, and be referenced to particular spatial scales. It also would need to be anchored in environmental factors which are functionally relevant to living organisms. The criteria of repeatability, global relevance, and functional relevance also apply to quantitative measurements of environmental variables along urban gradients.

These considerations rule out a number of commonly used or advocated measures. First, land zoning schemes used by planners are neither globally consistent nor do they capture the critical environmental features that are of functional significance to biota. Second, while surrogate measures such as spatial distance from urban cores, and age of suburb have region-specific predictive power, they are likely to vary from one region to another in their relationship with the functionally relevant features which they represent. Hence similar values of these surrogates will have different biological meanings in different regions. Measurements of human density share some of the weaknesses of both.

Biologically useful measurements would need to directly incorporate aspects of the land cover contributed by built structures, and by different forms of vegetation. These factors are both important to living organisms in their own right (as places to live, in providing food resources, etc), and also correlated with other ecologically significant factors (e.g. predation risk). Other factors, such as chemical inputs (nutrients, pollutants) and hydrology are also important, but may be more difficult to incorporate. This does not imply that other correlates, such as human density, should not be considered. However, they should not be expected to substitute for the more relevant measurements when comparisons across regions or countries, with differing culturally-determined land use patterns, are made.

Alberti et al. (2001) analysed remotely-sensed land cover measurements in the Seattle (USA) region, and obtained six categories of land cover: paved urban, grass/shrub urban, forested urban, grass/shrub/crops, deciduous forest, and coniferous forest. It is encouraging that these show a high level of consistency with the types of category used in the Brisbane region case study (in which bare suburbs and treed suburbs correspond with grass/shrub urban and bare urban), which were based on subjective judgment informed by local knowledge, ecological concepts and ground-based visual assessments. Seattle and Brisbane have many socioeconomic similarities, which may limit the global applicability of these categories.

\section{Concluding remarks}

I have argued that existing ecological principles and methods can be applied to provide understanding of the ecological processes that control changes in biodiversity within the urban 
biome, in a manner comparable with studies of more 'natural' biomes. Already, a picture is emerging of some of the higher-level ecological characteristics of terrestrial biotic assemblages in urban ecosystems: substantial multi-scale patchiness and beta-diversity; global biotic homogenisation within some urban patch types; non-equilibrial population and community dynamics; an important role for behavioural processes (e.g., dispersal, habitat selection, interspecific aggression); and a special role for relict vegetation patches spared from clearing. There may be unexpected parallels with other ecosystems. For example, in the tropical savannas of northern Australia, there are many scattered small patches of rainforest, considered relicts from an ancient, moister climatic regime. These make an important contribution to regional biodiversity, interact with the surrounding savanna matrix, and their persistence over thousands of years has been dependent on careful management decisions by Aboriginal people (though controlled burning; Bowman, 2000). Future ecological research in urban ecosystems may reveal whether there are shared principles. However, the scientific study of urban ecosystems still faces many challenges. I hope that the comments offered here will contribute to overcoming them.

\section{ACKNOWLEDGEMENTS}

I thank Sven Sewell, Kate Park, Mark Kingston, Anne Oertel, Scott Piper, Joss Bentley, Ronda Green, Darryl Jones, Terry Reis and John Kanowski for their various roles in generating the data sets analysed here. Particular thanks to Scott Piper for help with the data analyses presented here. Discussions with these people, and many others, have contributed to the development of themes and arguments pursued in this paper. Many other people contributed in various ways to the projects whose data were incorporated. I am grateful to Mark McDonnell, Kirsten Parris, and Jari Niemela for stimulating the production of this paper, and the conference presentation on which it was based.

\section{REFERENCES}

Alberti, M., Botsford, E. and Cohen, A. (2001). Quantifying the urban gradient: linking urban planning and ecology. In Avian Ecology And Conservation in an Urbanizing World, Marzluff, J., Bowman, R., and Donnelly, R. (eds). Boston: Kluwer Academic Publishers, pp 89-116.

Begon, M., Harper, J.L., and Townsend, C.R. (1990). Ecology. Individuals, Populations and Communities. Oxford: Blackwell Scientific Publications.

Bentley, J.M. and Catterall, C.P. (1997). The use of bushland, corridors and linear remnants by birds in south east Queensland, Australia. Conservation Biology 11: 1173-89.

Blair, R.B. (2001). Creating a homogeneous avifauna. Pp 459-486 In Avian Ecology and Conservation in an Urbanizing World, eds, Marzluff, J., Bowman, R. and Donnelly, R. Kluwer. Boston: Academic Publishers.

Blair, R.B. and Launer, A.E. (1997). Butterfly diversity and human land use: species assemblages along an urban gradient. Biological Conservation 80: 113-25.

Bolger, D.T. (2001). Urban birds: population, community, and landscape approaches. In Avian Ecology And Conservation in an Urbanizing World, eds. Marzluff, J., Bowman, R., and Donnelly, R. Boston: Kluwer Academic Publishers, pp 155-178

Bolger, D.T. (2002). Habitat fragmentation effects on birds in southern California: contract to the "top-down" paradigm. Studies in Avian Biology 25: 141-57.

Bowman, D.M.J.S. (2000). Australian Rainforests. Islands of Green in a Land of Fire. Cambridge: Cambridge University Press.

Bowman, R. and Martzluff, J. (2001). Integrating avian ecology into emerging paradigms in urban ecology. In Avian Ecology And Conservation in an Urbanizing World, eds. Marzluff, J., Bowman, R., and Donnelly, R. (eds). Kluwer Academic Publishers, Boston, pp 569-77 
Catterall, C.P. (1991). On the importance of watching birds. Wildlife Australia 28: 3-5.

Catterall, C.P. (2004). Birds, garden plants and suburban bush lots: where good intentions meet unexpected outcomes. In Urban Wildlife: More than Meets the Eye, eds. Burgin, S. and Lunney, D. Mosman, NSW: Royal Zoological Society of NSW, pp 21-31

Catterall, C.P. and Kingston, M. (1993). Human populations, bushland distribution in south eastern Queensland and the implications for birds. In Birds and Their Habitats: Status and Conservation in Queensland, eds. Catterall, C.P., Driscoll, P., Hulsman, K., and Taplin, A. Brisbane: Queensland Ornithological Society, pp. 105-122.

Catterall, C.P., Green, R.J., and Jones, D.N. (1989). The occurrence of birds in relation to plants in a subtropical city. Australian Wildlife Research 16: 289-305.

Catterall, C.P., Green, R.J., and Jones, D.N. (1991). Habitat use by birds across a forest-suburb interface in Brisbane: implications for corridors. In Nature Conservation 2, the Role of Corridors, eds. Saunders, D.A. and Hobbs, R.H. Chipping Norton: Surrey Beatty and Sons, pp 247-258

Catterall, C.P., Kingston, M.B., and Park, K. (1997a). Use of remnant forest habitat by birds during winter in subtropical Australia: patterns and processes. Pacific Conservation Biology 3: 26274.

Catterall, C.P., Storey, R.J. and Kingston, M.B. (1997b). Reality versus rhetoric: a case study monitoring regional deforestation. In Conservation Outside Nature Reserves, eds. Hale, P. and Lamb, D. Brisbane: Centre for Conservation Biology, University of Queensland, pp. 367-77

Catterall, C.P., Kingston, M.B., Park, K., and Sewell, S. (1998). Effects of clearing lowland eucalypt forests on a regional bird assemblage. Biological Conservation 84: 65-81.

Catterall, C.P. Piper, S., and Goodall, K. (2002). Noisy miner irruptions associated with land use by humans in south east Queensland: causes, effects and management implications. In Landscape Health of Queensland, eds. Franks, A., Playford, J., and Shapcott, A. Brisbane: Proceedings of the Royal Society of Queensland, pp. 117-27

Catterall, C.P., Kanowski, J., Wardell-Johnson, G., Proctor, H.C., Reis, T., Harrison, D.A., and Tucker, N.I.J. (2004). Quantifying the biodiversity values of reforestation: perspectives, design issues and outcomes in Australian rainforest landscapes. Conservation of Australia's Forest Fauna, $2^{\text {nd }}$ edn. (in press). ed. Lunney, D.

Clarke, K.R. (1993). Non-parametric multivariate analyses of change in community structure. Journal of Ecology 18: 117-43

Crooks, K.R., Suarez, A.V. and Bolger, D.T. (2004) Avian assemblages along a gradient of urbanization in a highly fragmented landscape. Biological Conservation 115: 451-62.

Dow, D.D. (1977). Indiscriminate interspecific aggression leading to almost sole occupancy of space by a single species of bird. Emu 77: 115-21.

Eberhardt, L.L. and Thomas, J.M. (1991). Designing environmental field studies. Ecological Monographs 6: 53-73.

Fahrig, L. (2003). Effects of habitat fragmentation on biodiversity. Annual Review of Ecology, Evolution and Systematics 34: 487-515.

Germaine, S.S. and Wakeling, B.F. (2001). Lizard species distributions and habitat occupation along an urban gradient in Tucson, Arizona, USA. Biological Conservation 97: 229-37.

Green, R.J. and Catterall, C.P. (1998). The effects of forest clearing and regeneration on the fauna of Wivenhoe Park, south east Queensland. Wildlife Research 25: 677-90.

Grey, M.J., Clarke, M.F. and Loyn, R.H. (1997). Initial changes in the avian communities of remnant eucalypt woodlands following a reduction in the abundance of noisy miners, Manorina melanocephala. Wildlife Research 24, 631-48.

Grey, M.J., Clarke, M.F. and Loyn, R.H. (1998). Influence of the noisy miner Manorina melanocephala on avian diversity and abundance in remnant grey box woodland. Pacific Conservation Biology 4, 55-69.

Harrison, S. and Bruna, E. (1999). Habitat fragmentation and large-scale conservation: what do we know for sure? Ecography 22: 225-32. 
Hochuli, D.F., Gibb, H., Burrows, S.E. and Christie, F.J. (2004). Ecology of Sydney's urban fragments: has fragmentation taken the sting out of insect herbivory? In Urban Wildlife: More than Meets the Eye.eds. Burgin, S. and Lunney, D. Mosman, NSW: Royal Zoological Society of NSW, pp 63-79

Hostetler, M. (2001). The importance of multi-scale analyses in avian habitat selection studies in urban environments. In Avian Ecology And Conservation in an Urbanizing World, eds. Marzluff, J., Bowman, R. and Donnelly, R. Boston: Kluwer Academic Publishers, pp 139-54

Hostetler, M. and Knowles-Yanez, K. (2003) Land use, scale, and bird distributions in the Phoenix metropolitan area. Landscape and Urban Planning 62: 55-68.

Lim, H.C. and Sodhi, N.S. (2004). Responses of avian guilds to urbanisation in a tropical city. Landscape and Urban Planning 66: 199-215

Low, T. (2002). The New Nature. Camberwell: Penguin Books.

Major, R.E., Gowing, G. and Kendal, C.E. (1996). Nest predation in Australian urban environments and the role of the pied currawong, Strepera graculina. Australian Journal of Ecology 21: 399409

Martin, T.G. and Catterall, C.P. (2001). Do fragmented coastal heathlands have habitat value to birds in eastern Australia? Wildlife Research 28: 1-15.

Marzluff, J. (2001). Worldwide urbanization and its effects on birds. In Avian Ecology And Conservation in an Urbanizing World, eds. Marzluff, J., Bowman, R. and Donnelly, R. Boston: Kluwer Academic Publishers, pp 19-48

Marzluff, J., Bowman, R. and Donnelly, R. (2001). A historical perspective on urban bird research: trends, terms, and approaches. In Avian Ecology And Conservation in an Urbanizing World, eds. Marzluff, J., Bowman, R. and Donnelly, R. Kluwer Academic Publishers, Boston, pp 1-80

McDonnell, M. J. and Pickett, S. T. A. (1990). Ecosystem structure and function along urban-rural gradients: an unexploited opportunity for ecology. Ecology 71: 1232-37.

McDonnell, M. J. and Pickett, S. T. A. (1993). Introduction: scope and need for an ecology of subtle human effects and populated areas. In Humans as components of ecosystems: the ecology of subtle human effects and populated areas, eds. McDonnell, M. J. and Pickett, S. T. A. New York: Springer-Verlag, pp 1-5.

McDonnell, M. J., Pickett, S. T. A. and Pouyat, R.V. (1993). The application of the ecological gradient paradigm to the study of urban effects. In Humans as components of ecosystems: the ecology of subtle human effects and populated areas, eds. McDonnell, M. J. and Pickett, S. T. A.. New York: Springer-Verlag, pp 175-89.

McDonnell, M.J, Pickett, S.T.A., Groffman, P, Bohlen, P., Pouyat, R.V., Zipperer, W.C., Parmelee, R.W., Carreiro, M.M. and Medley, K. (1997). Ecosystem processes along an urbanto-rural gradient. Urban Ecosystems 1: 21-36.

Melles, S., Glenn, S. and Martin, K. (2003). Urban bird diversity and landscape complexity: Species-environment associations along a multiscale habitat gradient. Conservation Ecology 7(1): 5. http://www.consecol.org/vol7/iss1/art5

Miller, J.R., Fraterrigo, J.M., Hobbs, N.T., Theobald, D. and Wiens, J.A. (2001). Urbanization, avian communities, and landscape ecology. In Avian Ecology And Conservation in an Urbanizing World, eds. Marzluff, J., Bowman, R. and Donnelly, R. Boston: Kluwer Academic Publishers, pp 117-38.

Niemala, J. (1999). Is there a need for a theory of urban ecology? Urban Ecosystems 3: 57-65

Niemela, J., Kotze, D. J., Venn, S., Penev, L., Stoyanov, I., Spence, J., Hartley, D. and de Oca, E.M. (2002). Carabid beetle assemblages (Coleoptera, Carabidae) across urban-rural gradients: an international comparison. Landscape Ecology 17: 387-401.

Oertel, A.S. (1998). Use of Small Eucalypt Forest Remnants by Birds in South East Queensland. B. Sc. (Hons) thesis, Griffith University, Brisbane.

Park, K., (1994). Aspects of Migration and Residency in Birds of Eucalypt Forests in South East Queensland. B.Sc. Hons. Thesis, Brisbane: Griffith University.. 
Parsons, H.M. and Major, R.E. (2004). Bird interactions in Sydney gardens: some initial findings of the Birds in Backyards program. In Urban Wildlife: More than Meets the Eye, eds. Burgin, S. and Lunney, D. Mosman, NSW: Royal Zoological Society of NSW, pp 211-15.

Parsons, H., French, K and Major, R.E. (2004) The influence of remnant bushland on the composition of suburban bird assemblages in Australia. Landscape and Urban Planning 66: 43-56

Patten, M. A. and Bolger, D. T. (2003). Variation in top-down control of avian reproductive success across a fragmentation gradient. Oikos 101: 479-88.

Pickett, S T R (1989). Space-for-time substitution as an alternative to long-term studies. In LongTerm Studies in Ecology: Approaches and Alternatives, ed. Likens, G.E. Springer-Verlag, pp 110-135.

Pickett, S.T.A., Burch Jr., W.R., Dalton, S.E., Foresman, T.W., Grove, J. M. and Rowntree, R. (1997). A conceptual framework for the study of human ecosystems in urban areas Urban Ecosystems 1: 185-99.

Piper, S.D. and Catterall, C.P. (2003). A particular case and a general pattern: hyperaggressive behaviour by one species may mediate avifaunal decreases in fragmented Australian forests. Oikos 101: 602-14.

Piper, S.D. and Catterall, C.P. (2004). Effects of edge type and nest height on predation of artificial nests within subtropical Australian eucalypt forests. Forest Ecology and Management 203: 361-372.

Quinn G.P. and Keogh M.J. (2002). Experimental Design and Data Analysis for Biologists. Cambridge: Cambridge University Press.

Reynaud, P.A. and Thiolouse, J. (2000). Identification of birds as biological markers along a neotropical urban-rural gradient (Cayenne, French Guiana), using co-inertia analysis. Journal of Environmental Management 59: 121-40.

Saunders, D.A., Hobbs, R.J. and Margules, C.R. (1991). Biological effects of ecosystem fragmentation: a review. Conservation Biology 5: 18-32.

Sewell, S and Catterall, C.P. (1998). Bushland modification and styles of urban development: their impacts on birds in south east Queensland. Wildlife Research 25: 41-64.

Watson, D.M. (2002) A conceptual framework for studying species composition in fragments, islands and other patchy ecosystems. Journal of Biogeography 29: 823-34.

Williams, M. (1993). An exceptionally powerful biotic factor. In Humans as components of ecosystems: the ecology of subtle human effects and populated areas, eds. McDonnell, M. J. and Pickett, S. T. A. New York: Springer-Verlag, pp 24-39. 
Table 1. Types of land cover compared, and sources of the information used in the case study.

\begin{tabular}{|c|c|c|c|c|}
\hline $\begin{array}{l}\text { Type of land } \\
\text { cover }\end{array}$ & $\begin{array}{l}\text { No. } \\
\text { of } \\
\text { sites }\end{array}$ & $\begin{array}{l}\text { No. } \\
\text { of } \\
\text { cases } \\
1\end{array}$ & $\begin{array}{c}\text { Data } \\
\text { sources }^{2,3}\end{array}$ & Description $^{4}$ \\
\hline Pasture & 5 & 1 & $\mathrm{a}$ & $\begin{array}{l}\text { Cleared areas of introduced pasture grasses grazed by } \\
\text { dairy cattle; some scattered trees and occasional } \\
\text { fences. }\end{array}$ \\
\hline Bare suburbs & 36 & 2 & b,c & $\begin{array}{l}\text { Suburbs with houses ( } 15-20 \mathrm{~m} \text { frontage), roads, and } \\
\text { gardens dominated by grassed lawns, and containing } \\
\text { very few scattered shrubs, or trees either native or } \\
\text { exotic. Negligible trees }>8 \mathrm{~m} \text {. }\end{array}$ \\
\hline Treed suburbs & 45 & 3 & $c(2), d$ & $\begin{array}{l}\text { Suburbs with houses ( } 15-30 \mathrm{~m} \text { frontage), roads, and } \\
\text { gardens with well-developed cover of taller trees and } \\
\text { shrubs, either native or introduced. Three } \\
\text { subcategories: 'canopy suburbs' ( } 17 \text { sites) where } \\
\text { residences and gardens were established beneath } \\
\text { thinned original canopy eucalypts; 'planted suburbs' } \\
\text { (20) containing gardens with many planted trees and } \\
\text { shrubs, a substantial proportion comprising } \\
\text { introduced species; 'gardens and parkland' (8) which } \\
\text { included some areas of planted suburb and some } \\
\text { grassy recreational areas with widely-spaced trees. }\end{array}$ \\
\hline $\begin{array}{l}\text { Eucalypt forest } \\
\text { remnants: }\end{array}$ & & & & See below \\
\hline $10-20$ ha & 28 & 2 & d,e & \\
\hline 4-10 ha & 35 & 2 & $c, d$ & \\
\hline 1-2 ha & 8 & 1 & d & \\
\hline $\begin{array}{l}\text { Eucalypt forest } \\
\text { tracts }>>100 \\
\text { ha }\end{array}$ & 96 & 6 & c,d,e,f(2),g & $\begin{array}{l}\text { Broadly characterised by a } 30-70 \% \text { canopy of tall } \\
\text { sclerophyllous trees of Eucalyptus and allied genera, } \\
\text { above a structurally moderately complex understorey } \\
\text { of small trees, shrubs and tall grasses. }\end{array}$ \\
\hline Rainforest & 10 & 1 & $\mathrm{a}$ & $\begin{array}{l}\text { Canopy cover of tall trees generally above } 70 \% \text {, high } \\
\text { floristic diversity of characteristic, mainly broad- } \\
\text { leaved genera, highly complex multi-layered } \\
\text { vegetation structure, ground layer of dense leaf litter. }\end{array}$ \\
\hline Total & 263 & 18 & 7 & \\
\hline \multicolumn{5}{|c|}{$\begin{array}{l}{ }^{1} \text { A case is a land cover type containing replicate sites within a particular study, usually separated by }>1 \mathrm{~km} \text {. } \\
\text { Apart from pasture, the minimum no. of sites per case was } 8 \text {; many were } 16-20 \text {. }\end{array}$} \\
\hline \multicolumn{5}{|c|}{$\begin{array}{l}\text { S Sources: a Catterall et al. 2004, b Catterall et al. 1991, c Sewell and Catterall 1998, d Oertel 1998, e } \\
\text { Catterall et al. } 1998 \text { and unpublished, f Bentley and Catterall 1997, g Park 1994. Data collection occurred } \\
\text { in } 6 \text { different years, between } 1985 \text { and } 1990 .\end{array}$} \\
\hline \multicolumn{5}{|c|}{$\begin{array}{l}{ }^{3} \text { Birds at each site were sampled with a transect } 100 \text { by } 30 \mathrm{~m} \text {, visited } 6 \text { times on different days (usually in } \\
\text { the morning) for } 15 \text { minutes (excepting source (d) which used } 20 \text { minutes and (a) which used } 30 \text { minutes } \\
\text { to allow more difficult detection in dense rainforest) Data were from a successive winter (May-August) } \\
\text { and summer (October-January), } 3 \text { visits in each, except for source (b) which used } 2 \text { successive winters } \\
\text { (suburbs show little seasonal turnover) and source (a) which used } 2 \text { visits in each of February-April, June- } \\
\text { July, October-November. All birds known to be on or close above the transect were counted }\end{array}$} \\
\hline \multicolumn{5}{|c|}{$\begin{array}{l}{ }^{4} \text { See Sewell and Catterall (1998) and Catterall et al. (2004) for quantitative characterisations of vegetation } \\
\text { structure. The minimum patch area of broadly similar habitat around a site was } 20 \text { ha, except for eucalypt } \\
\text { forest remnants of specified sizes and some rainforest sites. Transects were placed as far as possible from } \\
\text { the edges of remnant atches. and }>200 \mathrm{~m} \text { (often much more) from edges. }\end{array}$} \\
\hline
\end{tabular}


Table 2. Results of pairwise tests of similarity $^{1}$ in bird species composition ${ }^{2}$ among types of site that vary in land cover (numbers of sites shown in brackets). Values in each cell are $\mathrm{R}$ dissimilarity statistic above, $P$ below. Bolded cells show land cover types whose bird assemblages did not differ significantly. Global $\mathrm{R}=0.44, \mathrm{P}<0.001$.

\begin{tabular}{cccccccc}
\hline & $\begin{array}{c}\text { Bare } \\
\text { suburb } \\
(36)\end{array}$ & $\begin{array}{c}\text { Treed } \\
\text { suburb } \\
(45)\end{array}$ & $\begin{array}{c}1-2 \text { ha }^{\text {remnant }} \\
(8)\end{array}$ & $\begin{array}{c}4-10 \text { ha }^{3} \\
\text { remnant }^{3} \\
(35)\end{array}$ & $\begin{array}{c}10-20 \text { ha }^{3} \\
\text { remnant }^{3} \\
(28)\end{array}$ & $\begin{array}{c}\text { Eucalypt } \\
\text { forest }^{(96)}\end{array}$ & $\begin{array}{c}\text { Rain forest } \\
(10)\end{array}$ \\
\hline Pasture & 0.68 & 0.94 & 0.73 & 0.82 & 0.94 & 0.84 & 0.93 \\
$(5)$ & $<0.001$ & $<0.001$ & $<0.001$ & $<0.001$ & $<0.001$ & $<0.001$ & $<0.001$ \\
Bare & & 0.40 & 0.47 & 0.58 & 0.79 & 0.73 & 0.93 \\
suburb & & $<0.001$ & $<0.001$ & $<0.001$ & $<0.001$ & $<0.001$ & $<0.001$ \\
Treed & & & 0.07 & 0.39 & 0.79 & 0.56 & 1.00 \\
suburb & & & 0.24 & $<0.001$ & $<0.001$ & $<0.001$ & $<0.001$ \\
$1-2$ ha & & & & -0.16 & 0.38 & 0.36 & 1.00 \\
remnant & & & & 0.96 & $<0.001$ & $<0.001$ & $<0.001$ \\
$4-10$ ha & & & & & 0.17 & 0.19 & 0.89 \\
remnant & & & & & $<0.001$ & $<0.001$ & $<0.001$ \\
$10-20$ ha & & & & & & -0.04 & 0.90 \\
remnant & & & & & & 0.76 & $<0.001$ \\
Eucalypt & & & & & & & 0.57 \\
forest & & & & & & & $<0.001$ \\
\hline
\end{tabular}

${ }^{1}$ ANOSIM (Clarke 1993), using Bray-Curtis dissimilarities.

${ }^{2}$ Bird data were the presence/absence of all recorded species (total 144) from a plot $100 \mathrm{X} 30 \mathrm{~m}$ at each site, surveyed for six visits of mainly 15-20 min (mostly 3 summer, 3 winter).

${ }^{3}$ All remnants were eucalypt forest. 


\section{Figure legends}

Figure 1. Effects of different types of land cover on bird species richness, overall and within functional groups based on origin, feeding, and body mass; land cover types are ordered from pasture, through suburbs of increasing vegetation cover, to native forests of increasing canopy extent and density. All remnants were eucalypt forest. Bars are standard errors; sample sizes (numbers of sites) in brackets below axes. Birds were recorded at each site from a plot $100 \mathrm{X} 30$ $\mathrm{m}$, surveyed for six visits of mainly 15-20 min (mostly 3 summer, 3 winter).

Figure 2. Response patterns in frequency of selected common bird species (graphs a-l), arranged to show progressively differing peak frequencies along the composite gradient of land cover type; ordered from pasture, through suburbs of increasing vegetation cover, to native forests of increasing canopy extent and density. Frequency is the proportion of sites at which the species was recorded, from a plot 100 X $30 \mathrm{~m}$, surveyed for six visits of mainly 15-20 min (mostly 3 summer, 3 winter); numbers of sites in brackets below axes. Species' scientific names: a. Hirundo neoxena; b. Passer domesticus; c. Sturnus vulgaris; d. Trichoglossus haematodus; e. Platycercus adscitus; f. Manorina melanocephala; g. Lichenostomus chrysops; h. Melithreptus albogularis; i. Rhipidura fuliginosa; j. Pachycephala pectoralis; k Meliphaga lewinii; l Gerygone mouki.

Figure 3. Suggested relationship between the number of species in three simplified response guilds (new arrivals, Aussi icons and foliphiles; see text for explanation; generalist species are ignored) and size of forest fragment, for eucalypt forests in urbanising areas of subtropical eastern Australia.. 

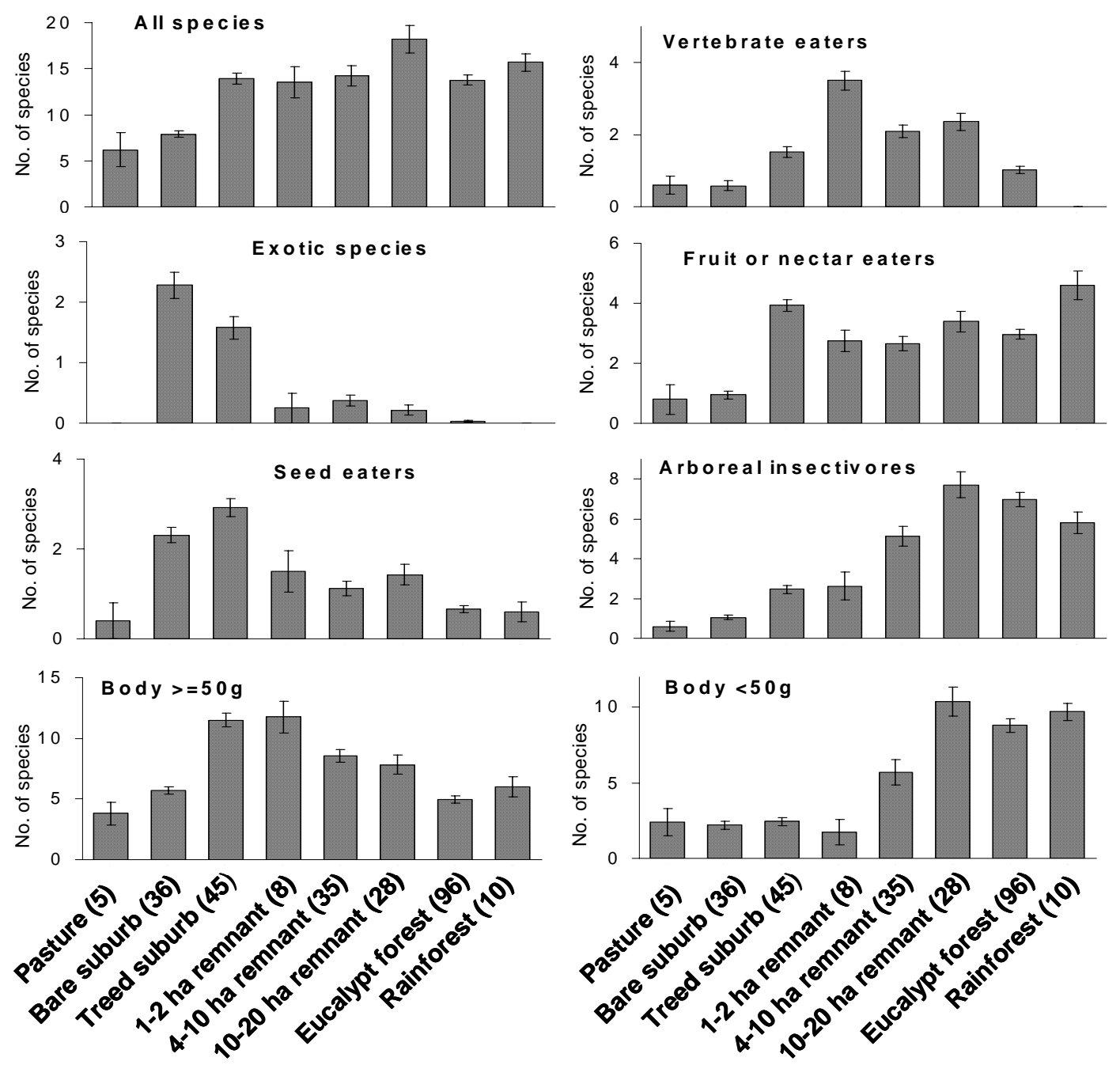


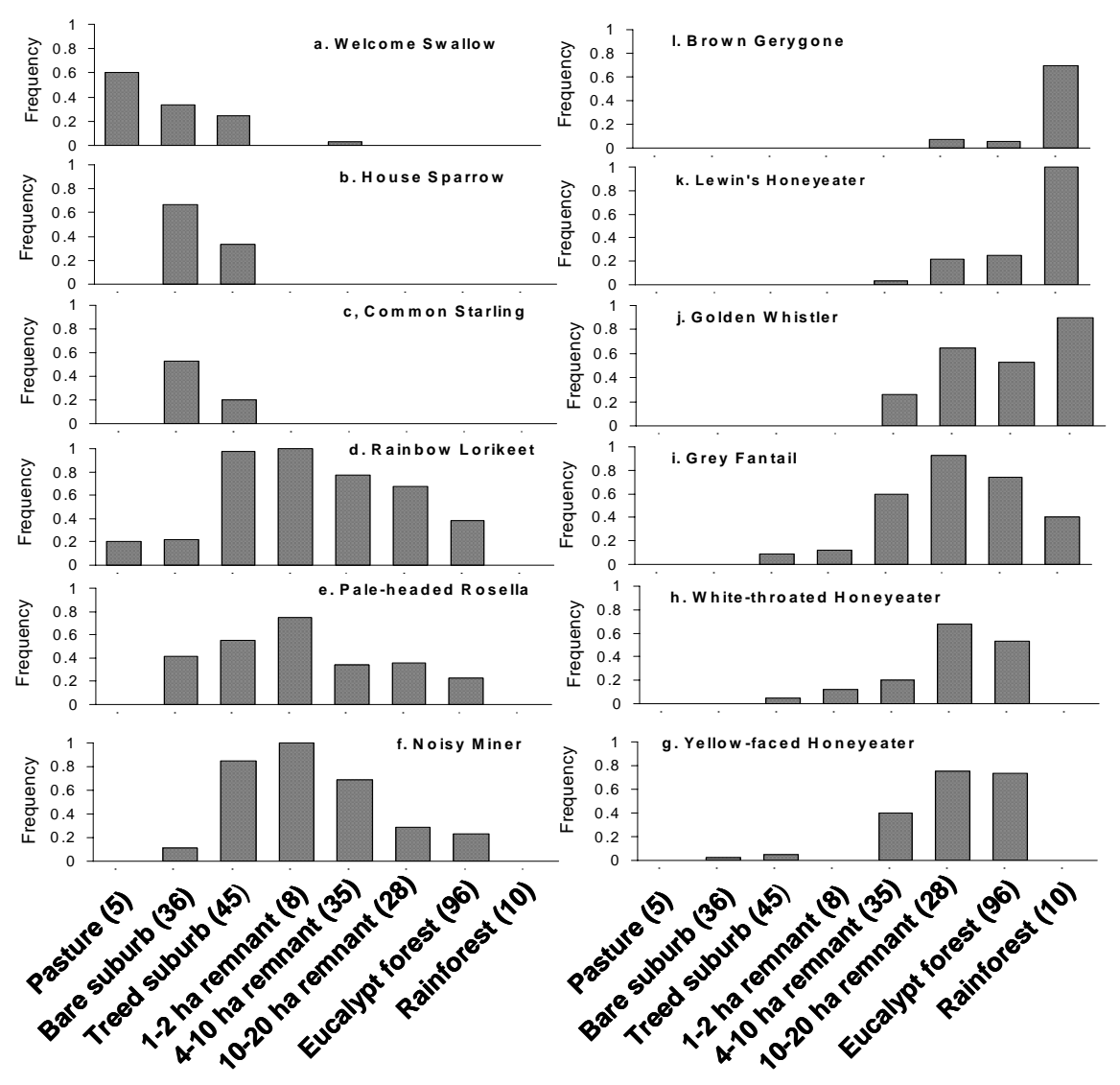




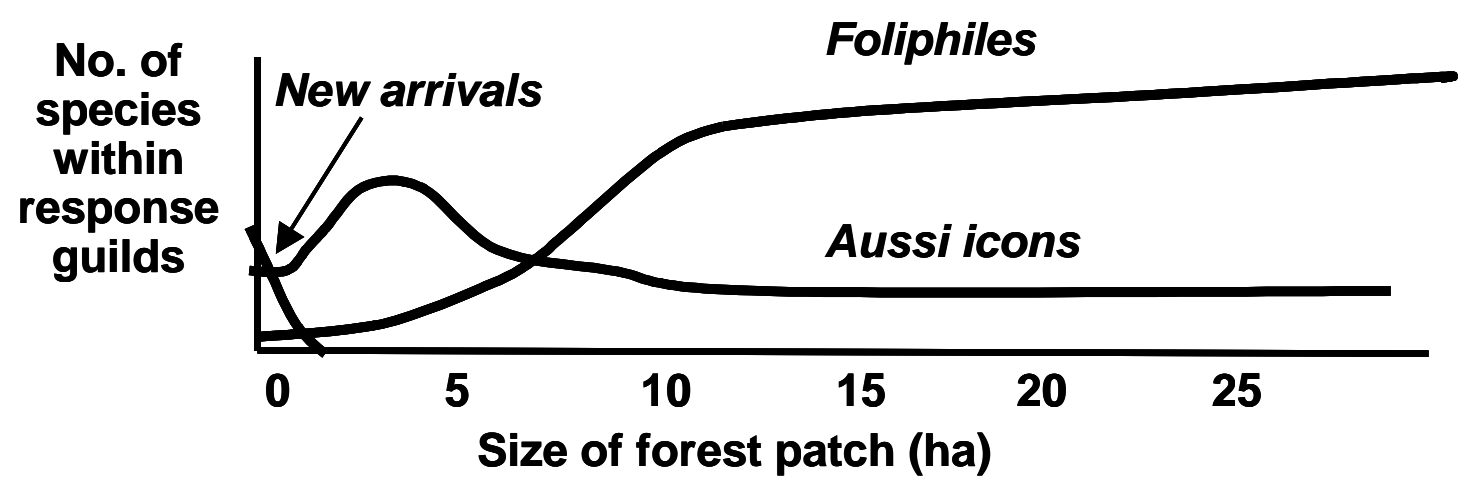

